\title{
Secuelas del maltrato en la infancia
}

\author{
Los jóvenes que han sufrido abuso \\ presentan una mayor tendencia \\ a beber alcohol
}

- Lorena Santos

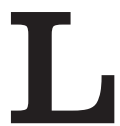

a Organización Mundial de la Salud expone que "aproximadamente un $20 \%$ de las mujeres y un 10\% de los hombres manifiestan haber sufrido abusos sexuales en la infancia, mientras que un $23 \%$ de las personas de ambos sexos menciona haber recibido maltratos físicos cuando era niño”. El investigador de la Universidad Miguel Hernández (UMH) de Elche Jorge Manzanares, en un proyecto conjunto con el profesor de Psiquiatría de la Universidad Complutense de Madrid Gabriel Rubio, analiza la tendencia del consumo de alcohol en la adolescencia en aquellos jóvenes que han sufrido maltrato. La investigación, financiada por el Plan Nacional sobre Drogas, ha servido para demostrar que "los adolescentes que han sufrido maltrato en su infancia consumen 30 veces más alcohol que aquellos que no han sido maltratados", como señala Rubio.

Las vivencias de la infancia son, en muchas ocasiones, causantes de problemas en la adolescencia como por ejemplo trastornos alimenticios, consumo de sustancias tóxicas, depresión, etc. Con este estudio, se pretende explicar lo que les ocurre a los pacientes a partir de modelos animales, en los que se puede concluir qué circuitos cerebrales y qué neurotransmisores estarían implicados en el abuso de alcohol. Gabriel Rubio ha registrado datos de 660 jóvenes, de entre 16 y 18 años, que han sufrido maltrato infantil: físico, sexual, psicológico o carente-afectivo. Estos datos se han obtenido por tres vías: centros dependientes del Ayuntamiento de Madrid en los que se ayuda a combatir las adicciones, centros de salud mental y centros de salud de atención primaria. "Se ha detectado que más de la mitad de estos jóvenes tienen problemas de abuso de sustancias, aunque no todos lo reconocen”, expone Rubio. También se ha demostrado, tal y como apunta el experto, que "cuanto más grave es el maltrato (físico en hombres y sexual en mujeres), mayor es el consumo de sustancias en la adolescencia”.

Por su parte, Jorge Manzanares ha analizado el comportamiento de ratones separados de la madre en el periodo postnatal. A partir del día 9 se separa a las crías -machos y hembras- de la madre durante unas horas y después se vuelven a juntar para, posteriormente, comprobar si esa separación ha creado algún rasgo de conducta especial. Manzanares expone que los resultados muestran una mayor tendencia de los machos a la ansiedad y la depresión, mientras que en las hembras es menos común. "No se observan trastornos cognitivos, aunque sí atencionales”, puntualiza el experto. "Después, en la adolescencia, hemos sometido a algunos de los animales a estrés y a todos ellos les enseñamos cómo autoadministrarse etanol, principal componente de las bebidas alcohólicas, para comprobar sus reacciones, sus tendencias y los cambios que se producen en el cerebro en cada una de las situaciones", explica el farmacólogo.

Las pruebas muestran 3 tipos de cambios a nivel cerebral, tal y como expone Jorge Manzanares. Uno tiene que ver con la regulación de los procesos de estrés, donde se produce una alteración en el sistema $\mathrm{Hi}$ potálamo Hipófisis Adrenal que es la vía del estrés; otro con la incapacidad de las células para regenerarse, los llamados procesos de neurogénesis; y un tercero muestra que los animales adolescentes que han sufrido estrés postnatal tienen menor número neuronas $y$, además, tienen el transmisor dopamina, responsable de las apetencias, alterado. 


\section{Los adolescentes en}

\section{el punto de mira de}

\section{la crisis económica}

Los Trastornos de la Conducta Alimentaria (TCA), como la anorexia y la bulimia, tienen su origen en la infancia y en la adolescencia, etapas que también son focos de aparición de otros problemas como alcoholemia o drogadicción. La profesora de Psicología de la UMH y coordinadora del Centro CREA, María José Quiles, explica que "la adolescencia es un momento complicado por la presión social que existe hacia la delgadez y el miedo al rechazo". Sin embargo, la escasez de financiación impide que muchos enfermos de este trastorno puedan recibir las atenciones que necesitan.

Hasta hace unos años, la Generalitat

Valenciana ofrecía una serie de convenios y financiaba el tratamiento en centros privados de los enfermos de TCA, pero ya no.

"Es importante que las familias cuenten con algo de financiación porque, ahora mismo, los recursos existentes no incluyen tratamientos intensivos y de control exhaustivo tras la salida del hospital", puntualiza Quiles. En el Hospital General Universitario de Alicante existe una unidad de TCA que tiene seis camas, pero en la que únicamente ingresan los enfermos con un índice de masa corporal muy bajo. Cuando reciben el alta hospitalaria disponen de consultas en centros de salud mental con psicólogos y psiquiatras, pero éstas están saturadas. En el centro CREA, que se define como un recurso intermedio entre los mencionados, se desarrollan tratamientos privados en los que hay una supervisión constante, lo que genera un coste elevado. Los miembros de CREA intentan buscar concierto con la sanidad pública para dar servicio a las familias sin acceso a los tratamientos ya que, aunque los servicios se ofrecen al mínimo coste posible, todavía hay familias que no pueden costear los gastos. Desde el centro, se llama la atención a particulares y empresas que quieran apoyar económicamente esta causa y ayudar a las familias.

www.creacentro.com/p/ubicacion.htm 